\title{
Age-specific population centiles for androgen status in men
}

\author{
D J Handelsman, B B Yeap ${ }^{1,2}$, L Flicker ${ }^{1,3}$, S Martin ${ }^{4}$, G A Wittert ${ }^{4}$ and Lam P Ly \\ Andrology, ANZAC Research Institute, University of Sydney, Sydney, New South Wales 2139, Australia, \\ ${ }^{1}$ School of Medicine and Pharmacology, University of Western Australia, Perth, Western Australia, Australia, \\ ${ }^{2}$ Department of Endocrinology and Diabetes, Fiona Stanley Hospital, Perth, Western Australia, Australia, \\ ${ }^{3}$ Western Australian Centre for Health and Aging, Centre for Medical Research, University of Western Australia, \\ Perth, Western Australia, Australia and ${ }^{4}$ Discipline of Medicine, University of Adelaide, Adelaide, \\ South Australia, Australia
}

Correspondence should be addressed to D J Handelsman Email djh@anzac.edu.au

\begin{abstract}
Aim: The age-specific population profiles in men of circulating testosterone and its two bioactive metabolites dihydrotestosterone (DHT) and estradiol $\left(E_{2}\right)$ across the adult lifespan and its determinants are not well described.

Objective: Our objective was to deduce smoothed age-specific centiles of circulating testosterone, DHT, and $E_{2}$ in men using pooled data from population-based studies in three Australian cities from liquid chromatography-mass spectrometry steroid measurements in a single laboratory.

Design, setting, and participants: We pooled data of 10904 serum samples (serum testosterone, DHT, E2, age, height, and weight) from observational population-based studies in three major cities across Australia.

Main outcome measures: Age-specific smoothed centiles for serum testosterone, DHT, and $E_{2}$ in men aged 35-100 years were deduced by large sample data analysis methods.

Results: We found that serum testosterone, $\mathrm{DHT}$, and $\mathrm{E}_{2}$ decline gradually from ages 35 onwards with a more marked decline after 80 years of age. Higher weight, BMI, and body surface area as well as shorter stature are associated with reduced serum testosterone, $\mathrm{DHT}$, and $\mathrm{E}_{2}$.

Conclusions: Among Australian men, there is a gradual progressive population-wide decline in androgen status during male aging until the age of 80 years after which there is a more marked decline. Obesity and short stature are associated with reduced androgen status. Research into the age-related decline in androgen status should focus on the progressive accumulation of age-related comorbidities to better inform optimal clinical trial design.
\end{abstract}

\section{Introduction}

Male reproductive health including spermatogenesis, fertility, virilization, and sexual function as well as androgen effects on non-reproductive target tissues are determined by the effects of testosterone together with its two bioactive metabolites dihydrotestosterone (DHT) and estradiol $\left(\mathrm{E}_{2}\right)$ (1). In men, virtually all testosterone is secreted by the Leydig cells of the testis into the circulation with subsequently $\sim 4 \%$ converted to DHT, a more potent, pure androgen by a $5 \alpha$-steroid reductase enzyme, and another $0.1 \%$ to $\mathrm{E}_{2}$ by aromatase. These (c) 2015 European Society of Endocrinology Printed in Great Britain bioactive steroids are transported via the bloodstream to reach their remote target tissues where testosterone and DHT both activate the androgen receptor (AR) and $E_{2}$, the estrogen receptor. Hence, a full appraisal of systemic androgen status in men requires concurrent consideration of all three bioactive sex steroids (2). Yet the age-specific population profile of circulating testosterone and its two bioactive metabolites across the lifespan is not well described through suitably large population-based studies using mass spectrometry (MS)-based steroid

Published by Bioscientifica Ltd. 
measurements. On this background, using a well-validated steroid profile by liquid chromatography (LC)-MS in a single laboratory and employing statistical methods suitable for large datasets, we deduced age-specific smoothed centiles from early adulthood until advanced old age using pooled data of over 10000 samples arising from population-based studies of men in three cities spanning across the Australian continent.

\section{Subjects and methods}

\section{Samples}

Early morning serum samples obtained from the following population-based studies of community-dwelling men, which have had their design, primary outcomes, and ethical review described in detail elsewhere, were analyzed for this study. In Perth, the Health in Men Study (HIMS) comprised a population-based cohort study of community-dwelling men (3). From the original cohort of 12203 men (wave 1, 1996-1999) randomly selected from the electoral roll, the second wave (4248 men, 2001-2004), then aged 70-89 years and over 95\% of European Caucasian descent, provided blood samples and were studied (4). In Adelaide, the Men, Androgens, Inflammation, Lifestyle, Environment and Stress (MAILES) study combined the harmonized populations of the Florey Adelaide Male Aging Study (FAMAS) (5), with blood samples collected between 2002 and 2005, and the male population of the North West Adelaide Health Study (NWAHS) (6), with blood samples collected between 2007 and 2010, both of which are prospective longitudinal cohort studies of randomly selected, community-dwelling adults, including men aged 35-86 years with over $96 \%$ of European Caucasian descent, in metropolitan Adelaide, Australia. Samples were obtained from two waves of the MAILES study with a median of 5 years between samples. In Sydney, the Concord Health and Aging in Men Project (CHAMP) comprised a population-based study of men of predominantly (>93\%) European Caucasian descent aged 70 years and over (range 70-99 years) living in a defined geographical region around Concord Hospital. The sampling frame was the New South Wales Electoral Roll noting that registration is compulsory in Australia (7). Blood samples were obtained from two waves of the study, between 2005 and 2007 and then again between 2007 and 2009, with a median of 2 years between samples. The population of these three cities, comprising 35\% of the national population, is similar and representative of the national population in demographic characteristics (see www.stat.abs.gov.au/itt/r.jsp?databyregion\#/), which supports the validity pooling the data for this analysis. In each city, the next most common ancestry was Asian with about half of Chinese descent.

\section{Sex steroid assays}

Serum samples had the same sex steroid profile measuring testosterone, DHT, and $\mathrm{E}_{2}$ in batch per study using a LCMS method as described (8). The steroid measurements were calibrated against certified reference materials for testosterone and DHT (National Measurement Institute, North Ryde, NSW, Australia) and $\mathrm{E}_{2}$ (European Commission's Institute for Reference Materials and Measurements) and had between-run coefficients of variation at three levels (low, medium, and high) of quality control (QC) specimens of $1.9-4.5 \%$ (testosterone), 3.8-7.6\% (DHT), and $2.9-13.6 \%\left(\mathrm{E}_{2}\right)$ over 184 runs that spanned the period of the samples included in this study. Overlapping QC samples were used continuously to span all of the batches measured in separate batches. Serum samples were stored frozen at $-80^{\circ} \mathrm{C}$ for up to 8 years prior to analysis, making it unlikely there was any influence of duration of storage on serum steroid measurements, which are stable in frozen storage for decades $(9,10,11)$.

\section{Statistical analysis}

Data were analyzed to deduce smoothed centiles using the General Additive Model for Location, Scale and Shape (GAMLSS), which adopts the LMS approach originally developed by Cole for pediatric growth charts $(12,13)$ and is related to the method of quantile regression developed for econometrics (14), using an implementation in R Software by Rigby \& Stasinopoulos $(15,16)$. For this analysis, the sample rather than the person was the primary unit of analysis. Where the same person was sampled in two different waves of a study (sampled at a median 4.2 years, range 2-6.3 years, between samples), each sample entered the analysis separately with its own specific age and blood hormone result at the time of sampling and was considered an independent sample for this analysis. Using the raw data, smoothed centiles $(1,2.5,5,10,25,50,75,90,95,97.5$, and 99) for the age-specific distribution of the serum, testosterone, DHT, and $\mathrm{E}_{2}$ were deduced. To better illustrate net androgen effects considering testosterone together with its more potent metabolite DHT as used previously, we defined a new variable serum androgen as the sum of serum testosterone plus five times serum DHT concentrations 
Table 1 Descriptive data of study population.

\begin{tabular}{l}
\hline Variable \\
\hline Age (years) \\
Height $(\mathrm{cm})$ \\
Weight $(\mathrm{kg})$ \\
$\mathrm{BSA}\left(\mathrm{kg} / \mathrm{m}^{2}\right)$ \\
BMI $\left(\mathrm{m}^{2}\right)$ \\
Serum testosterone $(\mathrm{nmol} / \mathrm{l})$ \\
Serum DHT $(\mathrm{nmol} / \mathrm{l})$ \\
Serum $\mathrm{A}^{\mathrm{a}}(\mathrm{nmol} / \mathrm{l})$ \\
Serum $\mathrm{E}_{2}$ (pmol/l) \\
DHT/testosterone ratio \\
$\mathrm{E}_{2} /$ testosterone ratio \\
\hline
\end{tabular}

\begin{tabular}{c}
\hline $\boldsymbol{n}$ \\
\hline 10904 \\
10876 \\
10879 \\
10869 \\
10869 \\
10902 \\
10466 \\
10902 \\
10070 \\
10460 \\
10064 \\
\hline
\end{tabular}

\begin{tabular}{c}
\hline Mean (s.D.) \\
\hline $68.7(11.2)$ \\
$172(7.2)$ \\
$82.0(13.8)$ \\
$1.99(0.19)$ \\
$27.7(4.0)$ \\
$14.6(6.3)$ \\
$1.47(0.79)$ \\
$16.3(6.7)$ \\
$84(38)$ \\
$0.12(0.76)$ \\
$9.4(32.2)$ \\
\hline
\end{tabular}

\begin{tabular}{c}
\hline Minimum \\
\hline 35.1 \\
147.5 \\
42.0 \\
1.38 \\
15.5 \\
0 \\
0 \\
0 \\
0 \\
0 \\
0 \\
\hline
\end{tabular}

\begin{tabular}{c}
\hline $\mathbf{Q 1}$ \\
\hline 65.5 \\
167 \\
72.8 \\
1.86 \\
25.0 \\
10.7 \\
0.96 \\
12.1 \\
61 \\
0.08 \\
4.5 \\
\hline
\end{tabular}

\begin{tabular}{c}
\hline $\mathbf{Q 2}$ \\
\hline 70.9 \\
172 \\
80.6 \\
1.98 \\
27.3 \\
14.0 \\
1.37 \\
15.7 \\
80 \\
0.10 \\
5.8 \\
\hline
\end{tabular}

\begin{tabular}{cccc}
\hline Q3 & & Maximum \\
\cline { 1 - 1 } 75.9 & & 99.2 \\
177 & & 208 \\
89.6 & & 167 \\
2.10 & & 2.95 \\
29.8 & & 60.4 \\
18.0 & & 91.6 \\
1.86 & & 18.9 \\
20.0 & & 102 \\
103 & & 1324 \\
0.12 & & 72.5 \\
7.5 & & 1163 \\
\hline
\end{tabular}

Q1, first quartile; Q2, second quartile (median); Q3, third quartile.

${ }^{a}$ Androgen is defined as the sum of serum testosterone plus five times the serum DHT reflecting the higher androgenic bioactivity of DHT. For details, see text.

(testosterone $+5 \times$ DHT) with the multiplier reflecting the fact that DHT has two- to tenfold higher intrinsic androgenic potency than testosterone $(17,18)$ due to its higher affinity and slower dissociation from the AR (19). For that definition where DHT was undetectable, a value of 0 was assigned. To reduce any impact of biological or analytical outliers, smoothed centiles of distributions were estimated using data trimmed (two-sided) by 1, 2, and 5\%. Preliminary analysis and sensitivity estimates (data not shown) resulted in defining the $2 \%$ trim as optimal for further robust analyses and was used for smoothed age-specific centile analyses. This means that a total of $4 \%$ samples were deleted including the highest $2 \%$ and the lowest $2 \%$ of samples prior to analysis. BMI was defined as weight/height ${ }^{2}$ and body surface area (BSA) by the Gehan-George formula (20).

\section{Results}

A summary of the descriptive data of all variables is presented in Table 1 and the age distribution of the study population is presented in Table 2 . The raw data of serum testosterone was the same in the complete data $(n=10897$ samples from 7921 men) and the data from first visit only ( $n=7921$ samples) showing a wide scatter that was substantially reduced by adjustment for height and weight (Fig. 1). Both also show a near identical distribution (Table 3). Both show a wide scatter of raw data, which was substantially reduced by adjustment for height and weight. All subsequent analyses used the complete data. A summary of the estimated centiles of serum testosterone for men under $65,65-75,75-85$, and over 85 years is presented in Table 4 .
The smoothed age-specific centiles for serum testosterone, DHT, androgen, and $\mathrm{E}_{2}$ are shown in Fig. 2. The smoothed centiles for serum testosterone according to height, weight, BMI, and BSA are shown in Fig. 3. Using linear regression (for comparison with previous studies), there was an age-related decrease in serum testosterone concentrations $(0.11 \mathrm{nmol} / \mathrm{l}$ or $0.5 \% /$ year $)$ and serum DHT $\left(0.01 \mathrm{nmol} / 1\right.$ or $0.5 \% /$ year) and to a lesser extent serum $\mathrm{E}_{2}$ ( $0.2 \mathrm{pmol} / 1$ or $0.2 \% /$ year). Increasing weight, BMI, and BSA and shorter height were associated with reduced serum testosterone. For each anthropometric measurement, the same pattern persisted after age-adjustment.

\section{Discussion}

A comprehensive evaluation of androgen status in men requires an appraisal of serum testosterone together with its bioactive metabolites DHT and $\mathrm{E}_{2}$ (2). Such appraisal first became practically feasible with MS-based multianalyte steroid profiling to provide a sensitive and specific

Table 2 Age distribution of study population.

\begin{tabular}{lcc}
\hline Age (years) & & $\boldsymbol{n}$ \\
\hline$<40$ & & 176 \\
$40-45$ & 399 \\
$45-50$ & 487 \\
$50-55$ & 489 \\
$55-60$ & 558 \\
$60-65$ & 497 \\
$65-70$ & 2310 \\
$70-75$ & 2828 \\
$75-80$ & 1956 \\
$80-85$ & 841 \\
$85-90$ & 270 \\
$>90$ & 86 \\
\hline
\end{tabular}




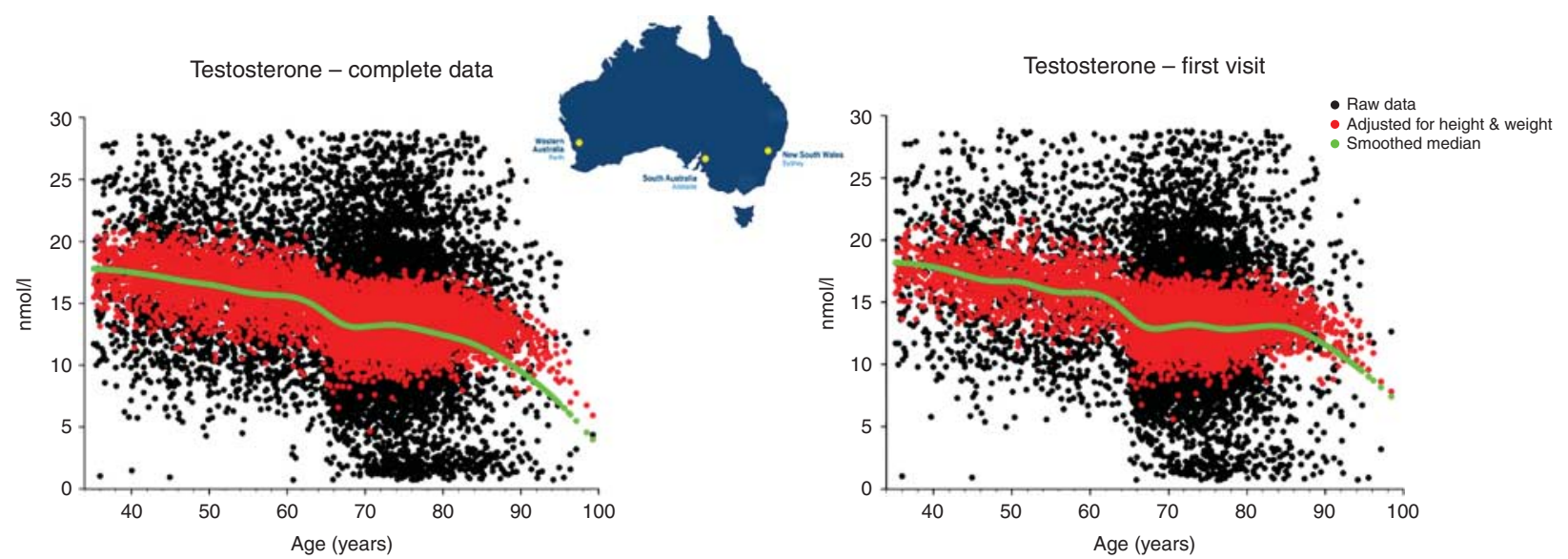

\section{Figure 1}

Serum testosterone concentrations measured by LC-MS in a single laboratory plotted as raw data (black dots), adjusted for height and weight (red dots), and a smoothed median (green line) from 10897 serum samples from 7921 men aged over 35 years from population-based studies in three Australian

simultaneous measurement of serum testosterone, DHT, and $\mathrm{E}_{2}$. The present study overcomes that limitation using a large, single dataset of samples ( $>10000)$ from pooling population-based studies from three major cities in a demographically homogenous national population all measured with the same LC-MS method. This method also reduces analytical variability by measuring both androgens and estrogens within a single run despite their different ionization optima. Additionally, we introduce large sample methods to deduce smoothed agespecific centiles from the fourth decade to advanced old age as well as to trim the dataset to eliminate potentially influential but uncharacterized outliers. The present approach is an advance on the largest previous population-based studies $(21,22)$, which pool data from different countries involving greater between-center heterogeneity in ethnicity, sociocultural and demographic factors than used herein by the pooling of centers with similar demography within a single country. Furthermore, serum DHT was rarely measured in population-based studies as few in-house DHT immunoassays were available and none in multiplex or valid single-tube formats (23). Similarly, serum $\mathrm{E}_{2}$ was usually measured by direct immunoassays, which are inaccurate at the low circulating $\mathrm{E}_{2}$ levels prevailing in men of all ages $(24,25,26)$. Finally, few studies reported measuring serum testosterone, DHT, and $\mathrm{E}_{2}$ in studies of thousands of participants $(21,22)$. cities. The left panel displays the complete data from 10897 samples while the right panel uses only the first samples from 7921 men. A full colour version of this figure is available at http://dx.doi.org/10.1530/EJE-15-0380.

Distinctive findings from this study include that men's serum testosterone, DHT, and $\mathrm{E}_{2}$ decline gradually during aging. These findings differ from a compilation of data from 13 different studies showing a minimal decline but increased variability in serum testosterone until the men are in their late 1980s (27). The increased variability may reflect a limitation that all but two studies used direct (non-extraction) testosterone immunoassays and interpolated an estimate of MS-equivalent serum testosterone

Table 3 Distribution of serum testosterone in complete and first visit data.

\begin{tabular}{lccc}
\hline \multicolumn{1}{c}{ Variable } & Complete data & First visit \\
\cline { 1 - 2 } Mean & 10428 & 7653 \\
S.E.M. & 14.1 & 14.0 \\
S.D. & 0.1 & 0.1 \\
Minimum & 5.5 & 5.4 \\
Maximum & 0.7 & 0.7 \\
Percentiles & 28.8 & 28.8 \\
1 & & \\
5 & 1.5 & 1.7 \\
10 & 4.9 & 5.7 \\
25 & 7.5 & 7.7 \\
50 & 10.6 & 10.4 \\
75 & 13.8 & 13.6 \\
90 & 17.7 & 17.4 \\
95 & 21.6 & 21.3 \\
99 & 24.0 & 23.7 \\
\hline
\end{tabular}


Table 4 Estimated centiles for men aged $<65,65-75,75-85$, and $>85$ years of age.

\begin{tabular}{|c|c|c|c|c|c|c|c|c|c|c|c|c|c|c|c|c|}
\hline & \multicolumn{4}{|c|}{ Testosterone $(\mathrm{nmol} / \mathrm{l})$} & \multicolumn{4}{|c|}{ DHT (nmol/l) } & \multicolumn{4}{|c|}{ Androgen $^{\mathrm{a}}(\mathrm{nmol} / \mathrm{l})$} & \multicolumn{4}{|c|}{ Estradiol (pmol/l) } \\
\hline & $<65$ & $65-75$ & $75-85$ & $>85$ & $<65$ & $65-75$ & $75-85$ & $>85$ & $<65$ & $65-75$ & $75-85$ & $>85$ & $<65$ & $65-75$ & $75-85$ & $>85$ \\
\hline$n$ & 2606 & 5141 & 2797 & 358 & 2401 & 4982 & 2725 & 358 & 2606 & 5141 & 2797 & 358 & 2034 & 4945 & 2733 & 358 \\
\hline $1 \%$ & 6.1 & 0.2 & 0.1 & 0.1 & 0.7 & 0.2 & 0 & 0 & 6.9 & 0.4 & 0 & 0 & 32 & 12 & 13 & 17 \\
\hline $2.5 \%$ & 7.6 & 2.1 & 0.3 & 0.1 & 0.8 & 0.3 & 0 & 0 & 8.9 & 2.2 & 0.2 & 0 & 38 & 23 & 22 & 22 \\
\hline $5 \%$ & 8.7 & 5.5 & 3.4 & 0.3 & 0.8 & 0.4 & 0.3 & 0 & 10.9 & 3.8 & 2.0 & 0.1 & 47 & 33 & 34 & 32 \\
\hline $25 \%$ & 12.9 & 10.2 & 10.1 & 8.1 & 1.2 & 0.9 & 0.9 & 0.7 & 18.6 & 10.0 & 5.4 & 3.7 & 68 & 58 & 60 & 60 \\
\hline $50 \%$ & 16.5 & 13.1 & 13.6 & 13.3 & 1.6 & 1.3 & 1.3 & 1.2 & 24.1 & 17.5 & 8.2 & 5.5 & 88 & 77 & 81 & 85 \\
\hline $75 \%$ & 20.6 & 16.8 & 17.5 & 17.9 & 2.1 & 1.8 & 1.8 & 1.7 & 30.3 & 23.7 & 16.9 & 7.7 & 112 & 98 & 104 & 111 \\
\hline $95 \%$ & 27.9 & 23.8 & 25.5 & 23.6 & 3.0 & 2.8 & 2.7 & 2.6 & 41.3 & 34.1 & 30.7 & 10.6 & 168 & 138 & 148 & 160 \\
\hline $97.5 \%$ & 30.7 & 26.5 & 28.6 & 25.4 & 3.5 & 3.2 & 3.1 & 3.0 & 46.4 & 38.1 & 35.1 & 11.4 & 196 & 154 & 166 & 174 \\
\hline $99 \%$ & 34.7 & 29.2 & 32.6 & 30.9 & 4.2 & 3.8 & 3.5 & 3.5 & 52.1 & 45.7 & 41.1 & 18.1 & 228 & 176 & 198 & 207 \\
\hline
\end{tabular}

${ }^{a}$ Androgen is defined as the sum of serum testosterone plus five times the serum DHT reflecting the higher androgenic bioactivity of DHT. For details, see text.

levels assuming a linear correlation. However, as serum testosterone concentrations measured by direct immunoassay deviate non-linearly from MS measurements, especially at lower serum testosterone concentrations characteristic of older men (8), the increased variability may be due to the reliance on inaccurate re-calibration of
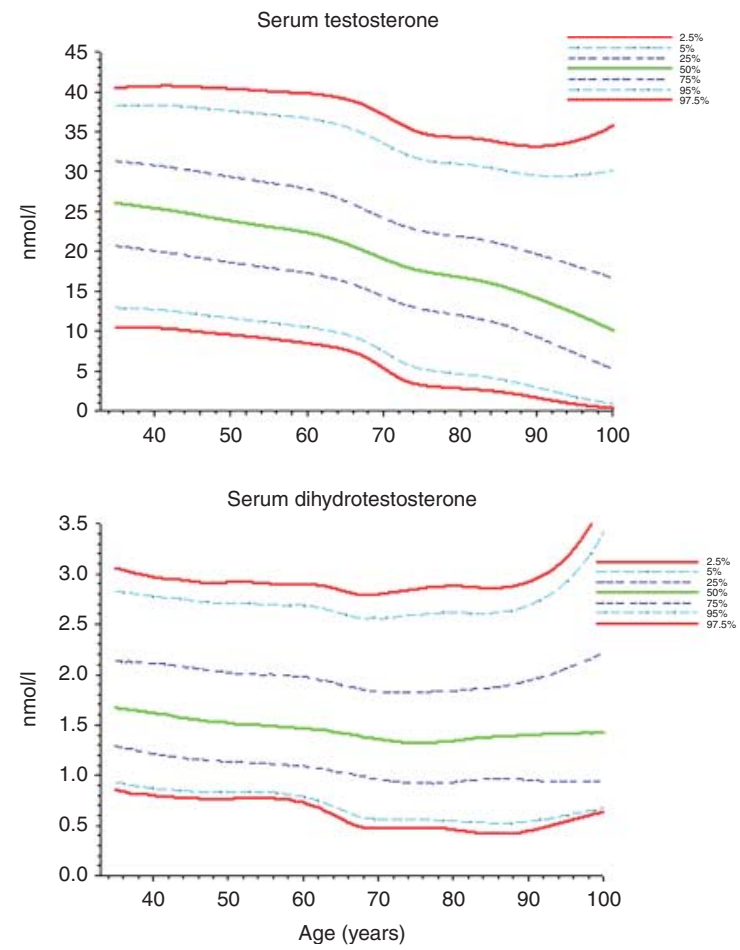

\section{Figure 2}

Plot of smoothed age-specific population centiles $(97.5,95,75$, $50,25,5$, and $2.5 \%)$ for serum testosterone (nmol/l), DHT ( $\mathrm{nmol} / \mathrm{l})$, androgen (nmol/l), and $E_{2}$ (pmol/l) in 10897 samples from men aged over 35 years from population-based studies in serum testosterone concentrations. In the present study the decline in serum testosterone and DHT are $\sim 0.5 \%$ /year, which is comparable but a little lower than previous estimates usually in the range of $0.8-2 \% / y e a r$ including those using MS-based methods (reviewed in $(28,29,30))$. Longitudinal estimates for rate of decline
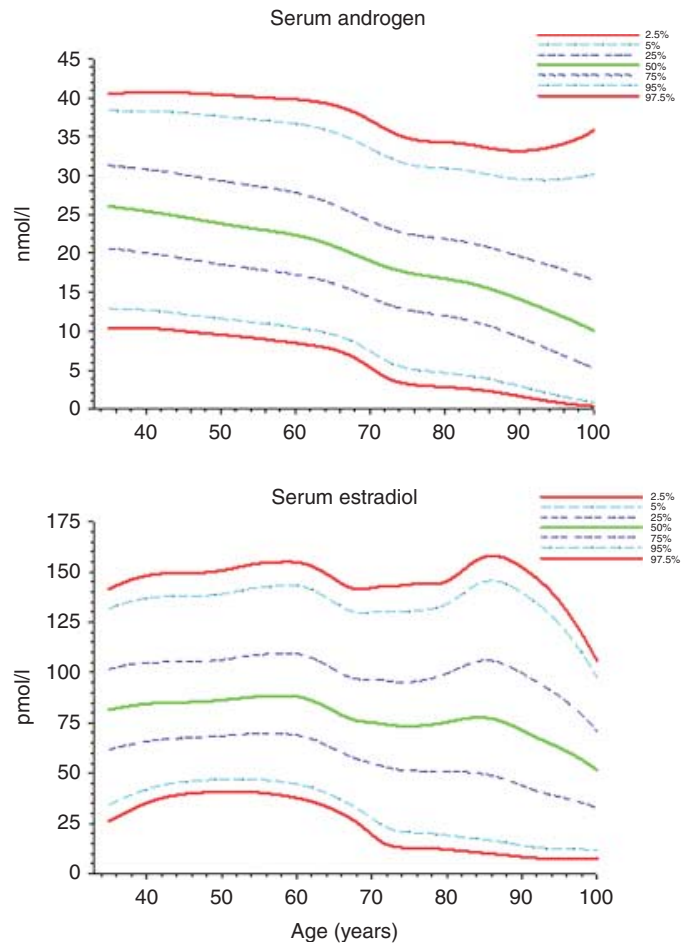

three Australian cities (Adelaide, Perth, and Sydney) using LC-MS steroid measurements from a single lab with data analysis using GAMLSS modeling. A full colour version of this figure is available at http://dx.doi.org/10.1530/EJE-15-0380. 

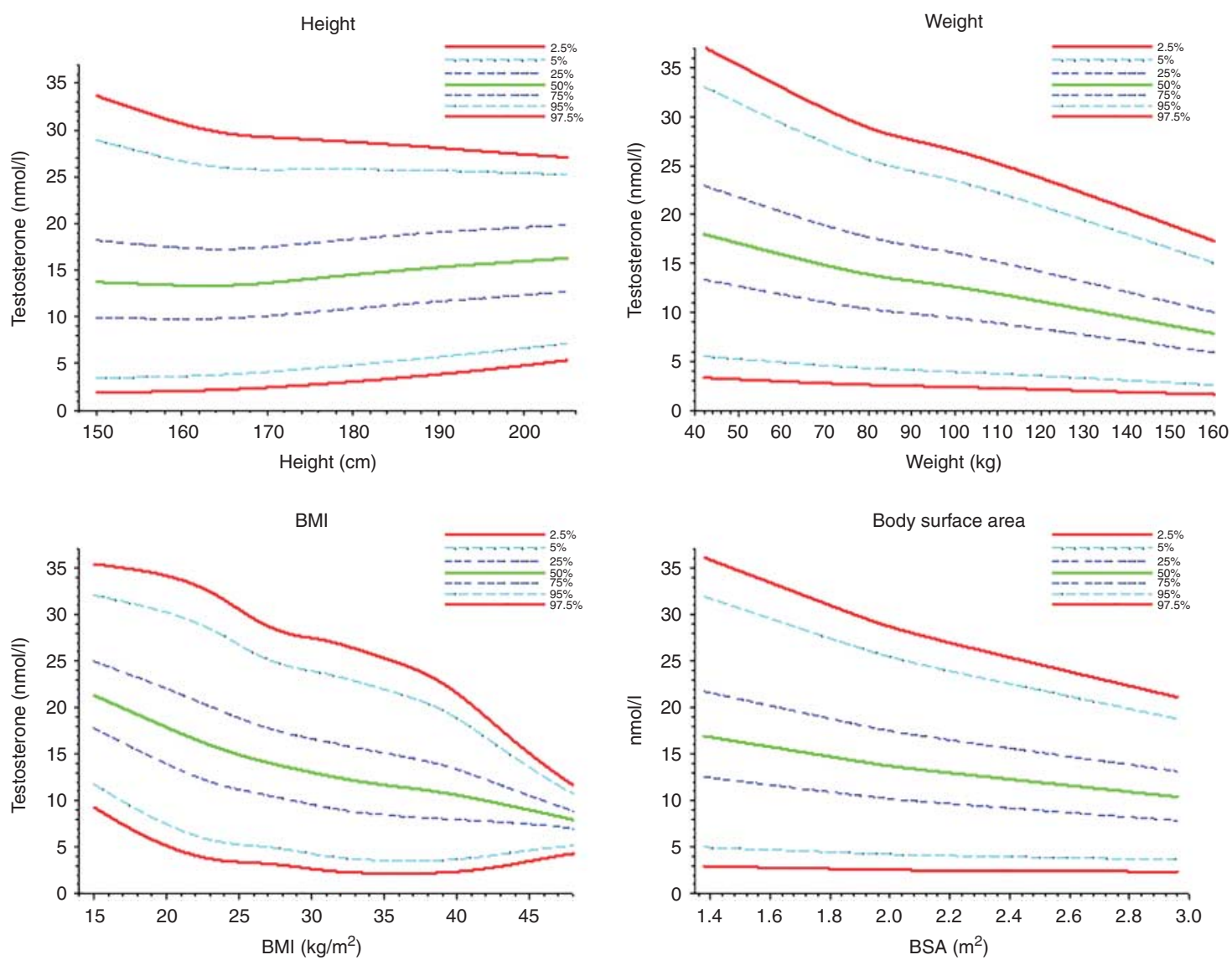

\section{Figure 3}

Plots of smoothed centiles $(97.5,95,75,50,25,5$, and $2.5 \%)$ of serum testosterone according to height $(\mathrm{cm})$, weight $(\mathrm{kg}), \mathrm{BMI}$ $\left(\mathrm{kg} / \mathrm{m}^{2}\right)$, and body surface area (BSA, $\left.\mathrm{m}^{2}\right)$ deduced by GAMLSS modeling from serum testosterone concentrations in 10897

are reportedly similar $(31,32)$ or higher $(33)$ than crosssectional annual estimates. The latter may reflect the population-wide temporal downward trend in serum testosterone (by immunoassay) reported in Denmark (34) and in one (35) of two USA studies (36) - trends that persist despite attempts to eliminate temporal changes in technical assay methodology and/or to increase population prevalence of obesity (37). An important interpretation of our findings is that an ageinvariant reference range for sex steroids in men is very wide. An alternative is to define age-specific reference intervals for androgen status as outlined in this study.

No comparable estimates of rates of age-related changes appear to be available for serum DHT or $\mathrm{E}_{2}$. In our study, age-specific serum DHT centiles showed a minimal decline before, but a marked decline after,

sera from men aged $>35$ years from population-based studies in three Australian cities. A full colour version of this figure is available at http://dx.doi.org/10.1530/EJE-15-0380.

65 years of age. Previous studies of serum DHT in men have reported no change $(38,39,40,41)$, an increase (33) or decrease (42) by age group in male aging using conventional RIAs or no change when measured by gas chromatography (GC)-MS (43).

Similarly, our finding of minimal changes in serum $\mathrm{E}_{2}$ is consistent with a comparable trend in serum $\mathrm{E}_{2}$ with age in the community-based Framingham Offspring Study (44) and our Healthy Man Study (45). Other previous studies have reported stable serum $\mathrm{E}_{2}$ levels with regard to male aging using conventional RIAs $(38,39,40,46)$ or GC-MS $(43,47,48)$, whereas studies using direct immunoassays reported no change $(49,50)$ or a decline $(51)$. Some of these discrepancies are likely due to the unreliability of $\mathrm{E}_{2}$ immunoassays at the low circulating levels prevailing in men $(24,25,26,52)$. 
The mechanism and significance of the biochemical decline in androgen status affecting aging men cannot be determined from the present observational study. Nevertheless, an important and plausible explanation is that this decline reflects the impact of the co-morbidities accumulating during aging on an otherwise healthy reproductive system. This is consistent with the findings that androgen status does not decline with aging among older men who remain in excellent (asymptomatic) health (45) although there is a decline associated with the co-morbidities of aging such as obesity, depression or cardiovascular disease. This is also consistent with the conclusions of other longitudinal studies $(31,32)$. Nevertheless, our cross-sectional study cannot fully exclude that age itself, apart from co-morbidities, might also contribute to declines in age-related serum testosterone, DHT, and $\mathrm{E}_{2}$ concentrations.

In this study, we utilize an illustrative response metameter to define net androgen status (53), defined as the sum of testosterone and DHT concentrations, using a weighting for DHT to reflect its higher androgenic potency. DHT is between two and ten times more potent than testosterone as an androgen, as measured by various mammalian and yeast $\mathrm{AR}$ bioassays $(17,18)$ and reflecting its higher affinity for, and greater stability of, AR binding with a slower dissociation rate compared with testosterone (19). The similarity of this index of androgen status with the temporal profile of testosterone and of DHT is consistent with the relative stability of the DHT/testosterone ratio (median 0.10) across a large population of men. Nevertheless, although DHT is usually converted from testosterone by $5 \alpha$ reductase, the independent backdoor pathway that synthesizes DHT bypassing testosterone (54) allows for independent regulation of serum DHT levels with potentially differential effects on health outcomes such as cardiovascular disease and mortality $(55,56)$. Hence, this novel response metameter, incorporating simultaneous measurements of both testosterone and DHT, may provide a more comprehensive metric to characterize androgen status for individual men and male populations where the impact on the two major androgens may diverge.

The study provided insight into the anthropometric determinants of serum testosterone, DHT, androgen, and $\mathrm{E}_{2}$. As expected, increasing weight, BMI, and BSA are associated with lower serum testosterone. A surprising finding is that short stature is associated with lower serum testosterone, an effect that was not due to confounding by age. A consequence of this finding is that height differences may be an unrecognized confounder of apparent racial differences in androgen status $(21,57)$.

Despite the strengths of this large, population-based study cohort using a single MS-based measurement and large sample data analysis methods, it has limitations. One is that the national population was predominantly Caucasian so the findings may not apply directly to other ethnic groups. Nevertheless, the small ethnic/racial differences reported in androgen status (57) are likely to be predominantly environmental rather than genetic $(58,59)$ so are likely minimized in this study. Like all comparable studies, another limitation is that it is notoriously difficult to distinguish age from a potentially confounding period or cohort effects, which are inevitably collinear with age (60).

We conclude that circulating testosterone, DHT, and $\mathrm{E}_{2}$ decline gradually during male aging. This age-associated decline may be due in part to the progressive impact of co-morbidities that accumulate during aging on a functionally intact reproductive system. Future research directed toward evaluating the mechanisms of the agerelated decline in androgen status should focus on the impact of co-morbidities of aging to better inform clinical trial design aiming to ameliorate late life somatic effects associated with aging.

Declaration of interest

The authors declare that there is no conflict of interest that could be perceived as prejudicing the impartiality of the research reported.

\section{Funding}

This research did not receive any specific grant from any funding agency in the public, commercial or not-for-profit sector.

\section{Author contribution statement}

D J Handelsman conceived, designed, directed the data analysis, and wrote the manuscript, L P Ly performed the data analysis, and all authors contributed to providing and interpreting the data and drafting the manuscript.

\section{References}

1 Handelsman DJ. Androgen physiology, pharmacology and abuse. In Endocrinology, pp 2469-2498. Eds LJ DeGroot \& JL Jameson, Philadelphia: Elsevier Saunders, 2010.

2 Handelsman DJ. Mechanisms of action of testosterone - unraveling a Gordian knot. New England Journal of Medicine 2013369 1058-1059. (doi:10.1056/NEJMe1305307)

3 Norman PE, Flicker L, Almeida OP, Hankey GJ, Hyde Z \& Jamrozik K. Cohort profile: The Health In Men Study (HIMS). International Journal of Epidemiology 200938 48-52. (doi:10.1093/ije/dyn041) 
4 Yeap BB, Alfonso H, Chubb SA, Handelsman DJ, Hankey GJ, Norman PE $\&$ Flicker L. Reference ranges and determinants of testosterone, dihydrotestosterone, and estradiol levels measured using liquid chromatography-tandem mass spectrometry in a population-based cohort of older men. Journal of Clinical Endocrinology \& Metabolism 2012 97 4030-4039. (doi:10.1210/jc.2012-2265)

5 Martin SA, Haren MT, Middleton SM \& Wittert GA. The Florey Adelaide Male Ageing Study (FAMAS): design, procedures \& participants. BMC Public Health 20077 126. (doi:10.1186/1471-2458-7-126)

6 Grant JF, Martin SA, Taylor AW, Wilson DH, Araujo A, Adams RJ, Jenkins A, Milne RW, Hugo GJ, Atlantis E et al. Cohort profile: the Men Androgen Inflammation Lifestyle Environment and Stress (MAILES) study. International Journal of Epidemiology 201443 1040-1053. (doi:10.1093/ije/dyt064)

7 Cumming RG, Handelsman D, Seibel MJ, Creasey H, Sambrook P, Waite L, Naganathan V, Le Couteur D \& Litchfield M. Cohort profile: the Concord Health and Ageing in Men Project (CHAMP). International Journal of Epidemiology 200938 374-378. (doi:10.1093/ije/dyn071)

8 Harwood DT \& Handelsman DJ. Development and validation of a sensitive liquid chromatography-tandem mass spectrometry assay to simultaneously measure androgens and estrogens in serum without derivatization. Clinica Chimica Acta 2009409 78-84. (doi:10.1016/j.cca. 2009.09.003)

9 Stroud LR, Solomon C, Shenassa E, Papandonatos G, Niaura R, Lipsitt LP, Lewinn K \& Buka SL. Long-term stability of maternal prenatal steroid hormones from the National Collaborative Perinatal Project: still valid after all these years. Psychoneuroendocrinology 200732 140-150. (doi:10.1016/j.psyneuen.2006.11.008)

10 Holl K, Lundin E, Kaasila M, Grankvist K, Afanasyeva Y, Hallmans G, Lehtinen M, Pukkala E, Surcel HM, Toniolo P et al. Effect of long-term storage on hormone measurements in samples from pregnant women: the experience of the Finnish Maternity Cohort. Acta Oncologica 2008 47 406-412. (doi:10.1080/02841860701592400)

11 Gislefoss RE, Grimsrud TK, Hoie K \& Morkrid L. Stability of testosterone measured in male archival serum samples by two different methods. Scandinavian Journal of Clinical \& Laboratory Investigation 201272 555-562. (doi:10.3109/00365513.2012.705888)

12 Cole TJ. The LMS method for constructing normalized growth standards. European Journal of Clinical Nutrition 1990 44 45-60.

13 Cole TJ \& Green PJ. Smoothing reference centile curves: the LMS method and penalized likelihood. Statistics in Medicine $1992 \mathbf{1 1}$ 1305-1319. (doi:10.1002/sim.4780111005)

14 Koenker R. Quantile regression. New York: Cambridge University Press, 2005.

15 Rigby RA \& Stasinopoulos DM. Smooth centile curves for skew and kurtotic data modelled using the Box-Cox power exponential distribution. Statistics in Medicine 200423 3053-3076. (doi:10.1002/sim.1861)

16 Rigby RA \& Stasinopoulos DM. Automatic smoothing parameter selection in GAMLSS with an application to centile estimation. Statistical Methods in Medical Research 201323 (4) 318-332.

17 Akram ON, Bursill C, Desai R, Heather AK, Kazlauskas R, Handelsman DJ $\&$ Lambert G. Evaluation of androgenic activity of nutraceutical-derived steroids using mammalian and yeast in vitro androgen bioassays. Analytical Chemistry 201183 2065-2074. (doi:10.1021/ac102845y)

18 Deslypere JP, Young M, Wilson JD \& McPhaul MJ. Testosterone and $5 \alpha$-dihydrotestosterone interact differently with the androgen receptor to enhance transcription of the MMTV-CAT reporter gene. Molecular \& Cellular Endocrinology 199288 15-22. (doi:10.1016/0303-7207 (92)90004-P)

19 Zhou ZX, Lane MV, Kemppainen JA, French FS \& Wilson EM. Specificity of ligand-dependent androgen receptor stabilization: receptor domain interactions influence ligand dissociation and receptor stability. Molecular Endocrinology 19959 208-218.

20 Bailey BJ \& Briars GL. Estimating the surface area of the human body. Statistics in Medicine 199615 1325-1332. (doi:10.1002/(SICI)10970258(19960715)15:13<1325::AID-SIM233>3.0.CO;2-K)
21 Orwoll ES, Nielson CM, Labrie F, Barrett-Connor E, Cauley JA, Cummings SR, Ensrud K, Karlsson M, Lau E, Leung PC et al. Evidence for geographical and racial variation in serum sex steroid levels in older men. Journal of Clinical Endocrinology \& Metabolism 201095 E151-E160. (doi:10.1210/jc.2009-2435)

22 Wu FC, Tajar A, Beynon JM, Pye SR, Silman AJ, Finn JD, O'Neill TW, Bartfai G, Casanueva FF, Forti G et al. Identification of late-onset hypogonadism in middle-aged and elderly men. New England Journal of Medicine 2010363 123-135. (doi:10.1056/NEJMoa0911101)

23 Yarrow JF, Beck DT, Conover CF, Beggs LA, Goldberger BA \& Borst SE. Invalidation of a commercially available human $5 \alpha$-dihydrotestosterone immunoassay. Steroids $2013 \mathbf{7 8} 1220-1225$. (doi:10.1016/j.steroids. 2013.08.013)

24 Huhtaniemi IT, Tajar A, Lee DM, O'Neill TW, Finn JD, Bartfai G, Boonen S, Casanueva FF, Giwercman A, Han TS et al. Comparison of serum testosterone and estradiol measurements in 3174 European men using platform immunoassay and mass spectrometry; relevance for the diagnostics in aging men. European Journal of Endocrinology 2012166 983-991. (doi:10.1530/EJE-11-1051)

25 Rosner W, Hankinson SE, Sluss PM, Vesper HW \& Wierman ME. Challenges to the measurement of estradiol: an Endocrine Society position statement. Journal of Clinical Endocrinology \& Metabolism 2013 98 1376-1387. (doi:10.1210/jc.2012-3780)

26 Handelsman DJ, Newman JD, Jimenez M, McLachlan R, Sartorius G \& Jones GR. Performance of direct estradiol immunoassays with human male serum samples. Clinical Chemistry 201460 510-517. (doi:10.1373/ clinchem.2013.213363)

27 Kelsey TW, Li LQ, Mitchell RT, Whelan A, Anderson RA \& Wallace WH. A validated age-related normative model for male total testosterone shows increasing variance but no decline after age 40 years. PLoS ONE 20149 e109346. (doi:10.1371/journal.pone.0109346)

28 Araujo AB \& Wittert GA. Endocrinology of the aging male. Best Practice \& Research. Clinical Endocrinology \& Metabolism 201125 303-319. (doi:10.1016/j.beem.2010.11.004)

29 Yeap BB. Hormones and health outcomes in aging men. Experimental Gerontology 201348 677-681. (doi:10.1016/j.exger.2012.07.012)

30 Kaufman JM \& Vermeulen A. The decline of androgen levels in elderly men and its clinical and therapeutic implications. Endocrine Reviews 200526 833-876. (doi:10.1210/er.2004-0013)

31 Shi Z, Araujo AB, Martin S, O'Loughlin P \& Wittert GA. Longitudinal changes in testosterone over five years in community-dwelling men. Journal of Clinical Endocrinology \& Metabolism 201398 3289-3297. (doi:10.1210/jc.2012-3842)

32 Camacho EM, Huhtaniemi IT, O'Neill TW, Finn JD, Pye SR, Lee DM, Tajar A, Bartfai G, Boonen S, Casanueva FF et al. Age-associated changes in hypothalamic-pituitary-testicular function in middle-aged and older men are modified by weight change and lifestyle factors: longitudinal results from the European Male Ageing Study. European Journal of Endocrinology 2013168 445-455. (doi:10.1530/EJE-12-0890)

33 Feldman HA, Longcope C, Derby CA, Johannes CB, Araujo AB, Coviello AD, Bremner WJ \& McKinlay JB. Age trends in the level of serum testosterone and other hormones in middle-aged men: longitudinal results from the Massachusetts Male Aging Study. Journal of Clinical Endocrinology \& Metabolism 200287 589-598. (doi:10.1210/jcem.87.2.8201)

34 Andersson AM, Jensen TK, Juul A, Petersen JH, Jorgensen T \& Skakkebaek NE. Secular decline in male testosterone and sex hormone binding globulin serum levels in Danish population surveys. Journal of Clinical Endocrinology \& Metabolism 200792 4696-4705. (doi:10.1210/ jc.2006-2633)

35 Travison TG, Araujo AB, O'Donnell AB, Kupelian V \& McKinlay JB. A population-level decline in serum testosterone levels in American men. Journal of Clinical Endocrinology \& Metabolism 200792 196-202. (doi:10.1210/jc.2006-1375)

36 Nyante SJ, Graubard BI, Li Y, McQuillan GM, Platz EA, Rohrmann S, Bradwin G \& McGlynn KA. Trends in sex hormone concentrations in 
US males: 1988-1991 to 1999-2004. International Journal of Andrology 201235 456-466. (doi:10.1111/j.1365-2605.2011.01230.x)

37 Corona G, Rastrelli G, Monami M, Saad F, Luconi M, Lucchese M, Facchiano E, Sforza A, Forti G, Mannucci E et al. Body weight loss reverts obesity-associated hypogonadotropic hypogonadism: a systematic review and meta-analysis. European Journal of Endocrinology 2013168 829-843. (doi:10.1530/EJE-12-0955)

38 Zumoff B, Strain GW, Kream J, O'Connor J, Rosenfeld RS, Levin J \& Fukushima DK. Age variation of the 24-hour mean plasma concentrations of androgens, estrogens, and gonadotropins in normal adult men. Journal of Clinical Endocrinology \& Metabolism 198254 534-538. (doi:10.1210/jcem-54-3-534)

39 Deslypere JP \& Vermeulen A. Leydig cell function in normal men: effect of age, life-style, residence, diet, and activity. Journal of Clinical Endocrinology \& Metabolism 198459 955-962. (doi:10.1210/jcem-59-5955)

40 Gray A, Feldman HA, McKinlay JB \& Longcope C. Age, disease, and changing sex hormone levels in middle-aged men: results of the Massachussetts Male Aging Study. Journal of Clinical Endocrinology \& Metabolism 199173 1016-1025. (doi:10.1210/jcem-73-5-1016)

41 Couillard C, Gagnon J, Bergeron J, Leon AS, Rao DC, Skinner JS, Wilmore JH, Despres JP \& Bouchard C. Contribution of body fatness and adipose tissue distribution to the age variation in plasma steroid hormone concentrations in men: the HERITAGE Family Study. Journal of Clinical Endocrinology \& Metabolism 200085 1026-1031.

42 Sparrow D, Bosse R \& Rowe JW. The influence of age, alcohol consumption, and body build on gonadal function in men. Journal of Clinical Endocrinology \& Metabolism 198051 508-512. (doi:10.1210/ jcem-51-3-508)

43 Belanger A, Candas B, Dupont A, Cusan L, Diamond P, Gomez JL \& Labrie F. Changes in serum concentrations of conjugated and unconjugated steroids in 40- to 80-year-old men. Journal of Clinical Endocrinology \& Metabolism 199479 1086-1090.

44 Jasuja GK, Travison TG, Davda M, Murabito JM, Basaria S, Zhang A, Kushnir MM, Rockwood AL, Meikle W, Pencina MJ et al. Age trends in estradiol and estrone levels measured using liquid chromatography tandem mass spectrometry in community-dwelling men of the Framingham Heart Study. Journals of Gerontology. Series A, Biological Sciences \& Medical Sciences 201368 733-740. (doi:10.1093/gerona/ gls216)

45 Sartorius G, Spasevska S, Idan A, Turner L, Forbes E, Zamojska A, Allan C, Ly L, Conway A, McLachlan R et al. Serum testosterone, dihydrotestosterone and estradiol concentrations in older men selfreporting very good health: the Healthy Man Study. Clinical Endocrinology 201277 755-763. (doi:10.1111/j.1365-2265.2012.04432.x)

46 Ferrini RL \& Barrett-Connor E. Sex hormones and age: a cross-sectional study of testosterone and estradiol and their bioavailable fractions in community-dwelling men. American Journal of Epidemiology 1998147 750-754. (doi:10.1093/oxfordjournals.aje.a009519)

47 Auyeung TW, Lee JS, Kwok T, Leung J, Ohlsson C, Vandenput L, Leung PC \& Woo J. Testosterone but not estradiol level is positively related to muscle strength and physical performance independent of muscle mass: a cross-sectional study in 1489 older men. European Journal of Endocrinology 2011164 811-817. (doi:10.1530/EJE-10-0952)

48 LeBlanc ES, Wang PY, Lee CG, Barrett-Connor E, Cauley JA, Hoffman AR, Laughlin GA, Marshall LM \& Orwoll ES. Higher testosterone levels are associated with less loss of lean body mass in older men. Journal of Clinical Endocrinology \& Metabolism 201196 3855-3863. (doi:10.1210/jc.2011-0312)
49 van den Beld AW, de Jong FH, Grobbee DE, Pols HA \& Lamberts SW Measures of bioavailable serum testosterone and estradiol and their relationships with muscle strength, bone density, and body composition in elderly men. Journal of Clinical Endocrinology \& Metabolism 2000 85 3276-3282.

50 Goemaere S, Van Pottelbergh I, Zmierczak H, Toye K, Daems M, Demuynck R, Myny H, De Bacquer D \& Kaufman JM. Inverse association between bone turnover rate and bone mineral density in community-dwelling men $>70$ years of age: no major role of sex steroid status. Bone 200129 286-291. (doi:10.1016/S87563282(01)00503-8)

51 Orwoll E, Lambert LC, Marshall LM, Phipps K, Blank J, BarrettConnor E, Cauley J, Ensrud K \& Cummings S. Testosterone and estradiol among older men. Journal of Clinical Endocrinology \& Metabolism 200691 1336-1344. (doi:10.1210/jc.2005-1830)

52 Handelsman DJ \& Wartofsky L. Requirement for mass spectrometry sex steroid assays in the Journal of Clinical Endocrinology \& Metabolism. Journal of Clinical Endocrinology \& Metabolism 201398 3971-3973. (doi:10.1210/jc.2013-3375)

53 Hsu B, Cumming RG, Seibel MJ, Naganathan V, Blyth FM, Bleicher K, Dave A, Le Couteur DG, Waite LM \& Handelsman DJ. Reproductive hormones and longitudinal change in bone mineral density and incident fracture risk in older men: The Concord Health and Ageing in Men Project. Journal of Bone \& Mineral Research 201530 1701-1708. (doi:10.1002/jbmr.2493)

54 Fukami M, Homma K, Hasegawa T \& Ogata T. Backdoor pathway for dihydrotestosterone biosynthesis: implications for normal and abnormal human sex development. Developmental Dynamics 2013242 320-329. (doi:10.1002/dvdy.23892)

55 Yeap BB, Alfonso H, Chubb SA, Handelsman DJ, Hankey GJ, Almeida OP, Golledge J, Norman PE \& Flicker L. In older men an optimal plasma testosterone is associated with reduced all-cause mortality and higher dihydrotestosterone with reduced ischemic heart disease mortality, while estradiol levels do not predict mortality. Journal of Clinical Endocrinology \& Metabolism 201499 E9-18. (doi:10.1210/jc.2013-3272)

56 Shores MM, Biggs ML, Arnold AM, Smith NL, Longstreth WT Jr, Kizer JR, Hirsch CH, Cappola AR \& Matsumoto AM. Testosterone, dihydrotestosterone, and incident cardiovascular disease and mortality in the cardiovascular health study. Journal of Clinical Endocrinology \& Metabolism 201499 2061-2068. (doi:10.1210/jc.2013-3576)

57 Richard A, Rohrmann S, Zhang L, Eichholzer M, Basaria S, Selvin E, Dobs AS, Kanarek N, Menke A, Nelson WG et al. Racial variation in sex steroid hormone concentration in black and white men: a metaanalysis. Andrology 20142 428-435. (doi:10.1111/j.2047-2927.2014. 00206.x)

58 Heald AH, Patel J, Anderson SG, Vyas A, Rudenski A, Hughes E, Panja NC, Ullah A, Prabhakaran D, Reddy S et al. Migration is associated with lower total, but not free testosterone levels in South Asian men. Clinical Endocrinology 200767 651-655. (doi:10.1111/j.1365-2265. 2007.02856.x)

59 Santner S, Albertson B, Zhang GY, Zhang GH, Santulli M, Wang C, Demers LM, Shackleton C \& Santen RJ. Comparative rates of androgen production and metabolism in Caucasian and Chinese subjects. Journal of Clinical Endocrinology \& Metabolism 199883 2104-2109.

$60 \mathrm{Tu}$ YK, Kramer N \& Lee WC. Addressing the identification problem in age-period-cohort analysis: a tutorial on the use of partial least squares and principal components analysis. Epidemiology 201223 583-593. (doi:10.1097/EDE.0b013e31824d57a9)

Received 26 May 2015

Revised version received 10 August 2015

Accepted 18 September 2015 